\title{
Efficacy of Orally Administered Febantel against Monogenean Heterobothrium okamotoi infection of Cultured Tiger Puffer Takifugu rubripes
}

\author{
Takeshi Kimura $^{1 *}$, Mamoru Sameshima1, Yoshinori Nomura² ${ }^{1}$ Jun Morita ${ }^{3}$, \\ Hideki Mizoguchi ${ }^{4}$ and Mamoru Ishihara ${ }^{3}$ \\ ${ }^{1}$ Kumamoto Prefectural Fisheries Development Division, Kumamoto 862-8570, Japan \\ ${ }^{2}$ Kumamoto Prefectural Fisheries Research Center, Kamiamakusa, \\ Kumamoto 869-3603, Japan \\ ${ }^{3}$ Agri-Vet Research, Pharmaceutical Research Center, Meiji Seika Kaisha, Ltd., \\ Yokohama 222-0002, Japan \\ ${ }^{4}$ Animal Helth Department, Research \& Development Agriculture \& Veternary \\ Division, Meiji Seika Kaisha, Ltd., Tokyo 104-8002, Japan
}

(Received May 29, 2006)

\begin{abstract}
We examined the efficacy of febantel against the infection of the diclidophorid monogenean Heterobothrium okamotoi in cultured tiger puffer Takifugu rubripes. Febantel is a prodrug of fenbendazole, a benzimidazole drug, which is widely used in the field of veterinary medicine. Febantel was metabolized to fenbendazole in tiger puffer just like veterinary animals for oral administration. At the doses of $12.5 \mathrm{mg} / \mathrm{kg}$ and $25 \mathrm{mg} / \mathrm{kg}$ for 5 days, and $50 \mathrm{mg} / \mathrm{kg}$ for 3 days, $88 \%, 96 \%$ and $94 \%$, respectively, of mature worms, and $97 \%, 95 \%$ and $97 \%$, respectively, of immature worms were eradicated at $22-23^{\circ} \mathrm{C}$. These results suggest that febantel has high anti- $H$. okamotoi activity.
\end{abstract}

Key words: Heterobothrium okamotoi, Takifugu rubripes, tiger puffer, febantel

Heterobothrium okamotoi is a blood-sucking parasite that inhabits on the gills and branchial cavity wall of cultured tiger puffer Takifugu rubripes. The disease caused by the parasite in cultured tiger puffers, referred to as the gill fluke disease, is potentially serious, as the parasites present in large numbers could cause severe anemia and eventually death of the fish (Okamoto, 1963). Since this parasite has not been detected in juvenile fish reared in hatcheries, it is thought that tiger puffers become infected with this parasite after their introduction to the culture field. $H$. okamotoi produces eggs with long filaments that become entangled on the net cage where their host fish are cultured (Ogawa and Inouye, 1997). Most of the deposited eggs become attached to the net meshing, resulting in the accumulation of eggs within the culture system, serving as a source of re-infection (Ogawa and Yokoyama, 1998).

\footnotetext{
* Corresponding author

E-mail: kimura-t-dz@pref.kumamoto.lg.jp
}

Fish farmers had been reported to use formalin to treat this gill fluke disease. However, the use of the chemical formalin as a drug for fish is prohibited in Japan, and the Kumamoto Prefectural government, in particular, strictly prohibits the use of formalin. Therefore, the demand for the development of a new effective drug against this gill fluke disease has been high among fish farmers.

Therefore, The Kumamoto Prefecture Fisheries Research Center began to develop for a new drug against this gill fluke disease with Meiji Seika Kaisha, Ltd. in 1998, we selected febantel among a hundred candidate drugs. Febantel is the prodrug of fenbendazole, which is a benzimidazole drug used widely in the field of veterinary medicine (Wollweber et al., 1978). Benzimidazoles, appear to act against glycogen synthesis and destroy the microtubular structure constituting the cell skeleton. Orally administered benzimidazoles have been shown to exhibit broad-spectrum anthelminthic activity in both human and veterinary medicine following 
absorption from the gastrointestinal tract (Lacey, 1990).

In the present research, we examined the pharmacokinetics of febantel after oral administration to healthy tiger puffer, in order to determine if the drug is also metabolized to fenbendazole in tiger puffer as in other animals (Baert et al., 1993; Debackere et al., 1993; BenZvi et al., 1996), and also if febantel, more specifically fenbendazole, is absorbed into blood of the host. We also report the potentially significant anti-H. okamotoi activity of febantel in both tiger puffer experimentally infected and those naturally infected with this parasite.

\section{Materials and methods}

Study 1: Measurement of the plasma concentrations of febantel and fenbendazole in tiger puffers following oral administration of febantel

Experimental fish Sixty-three, one-year-old healthy tiger puffers cultured at Kumamoto Prefectural Fisheries Research Center and free of $H$. okamotoi infection were used. The average body weight of the fish was $215 \mathrm{~g}$, and the fish were cultured in two-ton culture tanks with aeration at approximately $23.1^{\circ} \mathrm{C}$. Filtered seawater for the culture was circulated at the rate of $23 \mathrm{~L} / \mathrm{min}$.

Drugs Febantel 25\% (Meiji Seika Kaisha, Ltd.) was used for this study.

Feed The feeds used for the experiment were moist pellets (MPs) made from shrimp Neomysis intermedia, Japanese sand lance Ammodytes personatus, horse mackerel Trachurus japonicus, and assorted feeds using a disk pelleter. The experimental drug was mixed into these MPs, which were then stored at $-20^{\circ} \mathrm{C}$ until the administration. The fish were fed MPs not containing the drug at the rate of $1 \%$ of the body weight of the fish until the beginning of the drug administration.

Dosage of oral administration Febantel was administered singly at the dose of $25 \mathrm{mg} / \mathrm{kg}$ fish body weight. The fish were given MPs containing febantel at a feeding rate of $0.8 \%$ of the fish body weight.

Sampling and analysis Blood samples from the hepatic vein of five tiger puffers were collected in heparinized tubes immediately and at 4, 8, 12, 18, 24, 36, 48 and 72 $\mathrm{h}$ after the oral administration of febantel. Plasma samples were then prepared by centrifugation and stored at $-80^{\circ} \mathrm{C}$.

Febantel and fenbendazole concentrations were determined by HPLC after $0.5 \mathrm{~g}$ of the plasma was subjected to acetonitrile extraction, de-fatted with n-hexane, and purified using a Mega Bond Elut-C18 cartridge (Varian Inc., Palo Alto, CA). The concentration of febantel was measured by HPLC in a final volume of 0.5 $\mathrm{mL}$ under the following conditions: injection volume, 10 $\mu \mathrm{L}$, Wakosil $5 \mathrm{C} 18(\phi 4.6 \times 250 \mathrm{~mm}), 40^{\circ} \mathrm{C}$, the mobile phase composed of acetonitrile:purified water $(6: 4, \mathrm{v} / \mathrm{v})$, and the flow rate $1.0 \mathrm{~mL} / \mathrm{min}$. The concentration was determined based on the OD at $280 \mathrm{~nm}$.
Fenbendazole and its metabolite were measured as oxfendazole sulphone, formed by oxidation of fenbendazole and oxfendazole. After $0.5 \mathrm{~g}$ of the plasma was extracted with acetonitrile, de-fatted with nhexane and purified using a Mega Bond Elut-C18 cartridge, oxidation of fenbendazole and oxfendazole was allowed to occur by the addition of sulfuric acid and potassium permanganate, and the oxfendazole sulphone formed was extracted with chloroform. The concentration of oxfendazole sulphone was measured by HPLC in a final volume of $1.0 \mathrm{~mL}$, under the following conditions: an injection volume, $10 \mu \mathrm{L}$, Asahipak GS-320HQ ( $\phi 7.6$ $\mathrm{mm} \times 300 \mathrm{~mm}), 25^{\circ} \mathrm{C}$, the eluent composed of methanol: acetonitrile:ethanol $(6: 4: 2, \mathrm{v} / \mathrm{v} / \mathrm{v})$, and the flow rate 0.6 $\mathrm{mL} / \mathrm{min}$. The concentration of oxfendazole sulphone was determined by spectrophotometry with excitation at $254 \mathrm{~nm}$ and fluorescence at $415 \mathrm{~nm}$.

The concentrations of febantel and oxfendazole sulphone were calculated from the analytical curve using a reference standard. The limit of detection for both febantel and oxfendazole sulphone was $0.05 \mu \mathrm{g} / \mathrm{g}$. The recovery rates ( \pm coefficient of variation) of febantel and oxfendazole sulphone from the plasma were $94 \%( \pm$ $1.8 \%)$ and $72 \%( \pm 7.6 \%)$, respectively. The recovery test was carried out in three individuals.

To examine the bioavailability of febantel in tiger puffer based on the result of analysis for oxfendazole sulphone in the plasma, the following pharmacokinetic parameters were determined from the average concentration-time profiles: maximum drug concentration $\left(\mathrm{C}_{\max }\right)$, time to maximum drug concentration $\left(T_{\max }\right)$, and the halflife period $\left(T_{1 / 2}\right)$ in blood. The area under the blood concentration time curve (AUC) was calculated by the log-trapezoidal rule.

Study 2: Effects of febantel on $\mathrm{H}$. okamotoi in experimentally and naturally infected tiger puffers

Experimental fish In this study, one-year-old tiger puffers cultured in the Kumamoto Prefectural Fisheries Research Center were used. The mean body weight of the fish used for the experimental and natural infection studies were $108 \mathrm{~g}(\mathrm{n}=85)$ and $254 \mathrm{~g}(\mathrm{n}=25)$, respectively. Water temperature was about $25^{\circ} \mathrm{C}$ during the experimental infection study, or $22-23^{\circ} \mathrm{C}$ during the natural infection study.

Drugs The drug used was the same as that used in Study 1.

Feed The feed was the same as that used in Study 1. Experimental infection with $\mathrm{H}$. okamotoi The source of the eggs of $H$. okamotoi used for the experimental infection study was worms infecting about 40 three-year-old tiger puffers (average body weight, $2 \mathrm{~kg}$ ) in a culture tank at the Kumamoto Prefectural Fisheries Research Center. The eggs trapped in the drain pipe and the air tube of the culture tank were collected and incubated in $500-\mathrm{mL}$ culture flasks at $25^{\circ} \mathrm{C}$ after washing them with 
filtrated sea water. Oncomiracidia which began to hatch approximately 5 days afters the start of the incubation were used for infection experiment.

The fish were exposed to oncomiracidia at a rate of 251 larvae per fish for $3 \mathrm{~h}$. In this period the water circulation was stopped, but aeration was allowed to continue in the fish tanks (Chigasaki et al., 2000). Thereafter, the fish were distributed in equal numbers into five tanks $(500 \mathrm{~L})$ with active water circulation for 10 days. They were fed with the basal diet daily until febantel administration was started.

Counting of immature and mature parasites The number of immature worms was counted using the method described by Anshary et al. (2001), with some modification (Sameshima et al.,unpublished data.). In brief, tiger puffers were bled by cutting the hepatic vein, and their gills were removed and placed in a sample tube containing a $10 \%$ formalin seawater. The gills were mixed well using a magnetic stirrer for $10 \mathrm{~min}$ to remove the parasites. The formalin solution containing the gills and parasites was poured into a parasite-collecting set consisting of a plankton net (20 $\mu \mathrm{m}$ mesh) covered with a large mesh net (1 $\mathrm{mm}$, for collecting gills). The gills collected on the large mesh net were washed well with filtrered seawater, and the parasites collected onto the plankton net were also washed thrice with filtered

Table 1. Plasma concentration of febantel and oxfendazole sulphone in cultured tiger puffers following oral administration of febantel at the dose of $25 \mathrm{mg} / \mathrm{kg}$ body weight

\begin{tabular}{|c|c|c|c|c|c|c|c|c|c|}
\hline \multirow{3}{*}{$\begin{array}{c}\text { Fish } \\
\text { Number }\end{array}$} & & \multicolumn{8}{|c|}{ Concentration of febantel $(\mu \mathrm{g} / \mathrm{g})$} \\
\hline & & \multicolumn{8}{|c|}{ Time after adoministration (h) } \\
\hline & $\begin{array}{c}\text { Before } \\
\text { administration } \\
\text { (0) }\end{array}$ & 4 & 8 & 12 & 18 & 24 & 36 & 48 & 72 \\
\hline 1 & $<0.05$ & 1.5 & 0.35 & 0.18 & 0.09 & $<0.05$ & $<0.05$ & $<0.05$ & $<0.05$ \\
\hline 2 & $<0.05$ & $<0.05$ & 0.25 & 0.24 & 0.10 & 0.07 & $<0.05$ & $<0.05$ & $<0.05$ \\
\hline 3 & $<0.05$ & 0.36 & 0.07 & 0.20 & 0.08 & 0.07 & $<0.05$ & $<0.05$ & $<0.05$ \\
\hline 4 & $<0.05$ & 0.41 & $<0.05$ & 0.06 & 0.05 & $<0.05$ & $<0.05$ & $<0.05$ & $<0.05$ \\
\hline 5 & $<0.05$ & 0.59 & 0.19 & 0.10 & $<0.05$ & 0.07 & $<0.05$ & $<0.05$ & $<0.05$ \\
\hline average & $0^{*}$ & $0.58^{*}$ & $0.17^{*}$ & 0.16 & $0.07^{*}$ & $0.06^{*}$ & $0.05^{*}$ & $0.05^{*}$ & $0.05^{*}$ \\
\hline \multirow[t]{2}{*}{ S.D. } & & 0.55 & 0.14 & 0.07 & 0.02 & 0.01 & 0.00 & 0.00 & 0.00 \\
\hline & & \multicolumn{8}{|c|}{ Concentration of oxfendazole sulphone $(\mu \mathrm{g} / \mathrm{g})$} \\
\hline 1 & $<0.05$ & 13 & 11 & 8.8 & 5.3 & 7.1 & 1.5 & 0.58 & 0.24 \\
\hline 2 & $<0.05$ & 0.16 & 14 & 14 & 0.8 & 6.5 & 1.6 & 0.13 & $<0.05$ \\
\hline 3 & $<0.05$ & 6.3 & 4.0 & 9.4 & 12 & 4.1 & 2.3 & 2.7 & 0.61 \\
\hline 4 & $<0.05$ & 7.5 & 0.8 & 13 & 4.6 & 5.6 & 2.2 & 0.45 & 0.48 \\
\hline 5 & $<0.05$ & 9.0 & 10.0 & 6.2 & 6.7 & 5.6 & 0.66 & 1.2 & 0.42 \\
\hline average & $0^{*}$ & 7.2 & 8.0 & 10.3 & 5.9 & 5.8 & 1.7 & 1.0 & $0.36 *$ \\
\hline S.D. & & 4.7 & 5.4 & 3.2 & 4.1 & 1.1 & 0.66 & 1.0 & 0.22 \\
\hline
\end{tabular}

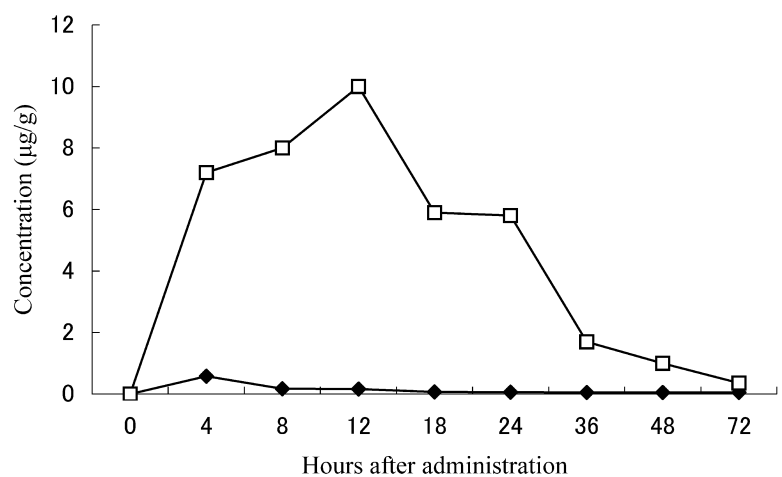

Fig. 1. The concentration-time profile of febantel and oxfendazole sulphone in the plasma after oral administration of febantel. The symbols $\bullet$ and $\square$ represent febantel and oxfendazole sulphone, respectively.
Table 2. Efficacy of febantel against immature $H$. okamotoi in experimentally infected tiger puffers $(n=8)$.

\begin{tabular}{lcc}
\hline \multirow{2}{*}{ Experimental group } & \multicolumn{2}{c}{ Immature worms } \\
\cline { 2 - 3 } & $\begin{array}{c}\text { Average no. } \\
\text { of worms }\end{array}$ & $\begin{array}{c}\text { Removal } \\
\text { rate }(\%)\end{array}$ \\
\hline Control & $73.6( \pm 20.0)$ & - \\
$25 \mathrm{mg} / \mathrm{kg} /$ day & $78.6( \pm 22.6)$ & $+6.8^{* *}$ \\
$50 \mathrm{mg} \mathrm{/kg} \mathrm{/} \mathrm{day}$ & $71.9( \pm 22.9)$ & -2.4 \\
$100 \mathrm{mg} / \mathrm{kg} /$ day & $83.0( \pm 20.1)$ & +12.8 \\
$50 \mathrm{mg} / \mathrm{kg} /$ day for 2days & $28.6( \pm 24.1)^{*}$ & -61.1
\end{tabular}

$*$ : significant difference $(p<0.05)$.

$* *$ : +, - increase and decrease in $\%$, respectively 
Table 3. Efficacy of febantel against mature and immature $H$. okamotoi in naturally infected tiger puffers $(n=8)$.

\begin{tabular}{lllllc}
\hline \multirow{2}{*}{ Experimental group } & \multicolumn{2}{c}{ Mature } & & \multicolumn{2}{c}{ Immature } \\
\cline { 2 - 3 } \cline { 6 - 7 } & $\begin{array}{c}\text { Average no. } \\
\text { of worms }\end{array}$ & $\begin{array}{c}\text { Removal rate } \\
(\%)\end{array}$ & & $\begin{array}{c}\text { Average no. } \\
\text { of worms }\end{array}$ & $\begin{array}{c}\text { Removal rate } \\
(\%)\end{array}$ \\
\hline Control & $7.1( \pm 8.1)$ & - & & $113.0( \pm 101.6)$ & - \\
$12.5 \mathrm{mg} / \mathrm{kg} /$ day for 5 days & $0.86( \pm 2.3)^{*}$ & 88 & & $3.3( \pm 4.3)^{*}$ & 97.1 \\
$25 \mathrm{mg} / \mathrm{kg} /$ day for 5 days & $0.29( \pm 0.8)^{*}$ & 96 & & $5.9( \pm 9.3)^{*}$ & 94.8 \\
$50 \mathrm{mg} / \mathrm{kg} /$ day for 3 days & $0.40( \pm 1.1)^{*}$ & 94 & & $3.3( \pm 3.9)^{*}$ & 97.1 \\
\hline
\end{tabular}

*: significant difference $(p<0.05)$.

seawater. The collected parasites were placed in Petri dishes and counted under a stereoscopic microscope. Mature worms on the branchial cavity wall were counted with tweezers after the removal of the gills.

In the experimental infection study, only immature worms were counted, while in the natural infection study both immature and mature worms were counted.

Dosage for oral administration In the experimental infection study, the drug was administered to the fish at doses of $25 \mathrm{mg}, 50 \mathrm{mg}$ and $100 \mathrm{mg} / \mathrm{kg}$ fish body weight for 1 day, and at the dose of $50 \mathrm{mg} / \mathrm{kg}$ for 1 or 2 days. Fish receiving MPs without the drug served as controls.

The number of immature parasites was counted at 7 days after the administration of febantel in eight tiger puffers from each tank.

In the natural infection study, the drug was administered orally to the fish at doses of $12.5 \mathrm{mg} / \mathrm{kg}$ and $25 \mathrm{mg} /$ $\mathrm{kg}$ for 5 days, and at the dose of $50 \mathrm{mg} / \mathrm{kg}$ for 3 days. Fish receiving MPs without the drug were used as the controls. The number of infected mature and immature worms was counted 3 days after the administration in eight tiger puffers from each tank.

The statistical significance level of the data was judged by Mann-Whitney's U-test $(p<0.05)$ by comparing the number of $H$. okamotoi detected between the control and experimental fish after the administration. The efficacy of febantel was shown according to the removal rate of worms, the following formula was used.

$$
\% \text { efficacy }=[1-(\mathrm{Pa} / \mathrm{Pb})] \cdot 100
$$

where $\mathrm{Pa}$ is the average number of worms detected after the drug administration and $\mathrm{Pb}$ is the number of worms detected in the controls.

\section{Results}

The plasma concentrations of febantel and fenbendazole in tiger puffers following oral administration of the drug at the dose of $25 \mathrm{mg} / \mathrm{kg}$ fish body weight are shown in Table 1. While fenbendazole (whose metabolite was measured based on the concentration oxfendazole sulphone) occurred at high concentrations, febantel was detected only at low concentrations. The concentration of febantel peaked at $4 \mathrm{~h}$ after the drug administration in all the fish and decreased to $30 \%$ of the peak at $8 \mathrm{~h}$ after the drug administration and decreased steadily thereafter. The concentration of oxfendazole sulphone peaked at $12 \mathrm{~h}$ after the drug administration in all the fish and the drug could be detected in the plasma even at $72 \mathrm{~h}$ after the administration. From these results, the $\mathrm{C}_{\max }$ of oxfendazole sulphone was determined as $10.3 \mu \mathrm{g} / \mathrm{g}$, the $T_{\max }$ of oxfendazole sulphone as $12 \mathrm{~h}$, and the $T_{1 / 2}$ of oxfendazole sulphone as $12.17 \mathrm{~h}$. The AUC of oxfendazole sulphone was $241.6 \mu \mathrm{g} / \mathrm{g}$. The concentration-time profiles of febantel and oxfendazole sulphone are shown in Fig. 1. The time course of changes in the concentration of oxfendazole sulphone shows the typical curve of a compartment model.

As for the efficacy of the febantel against $H$. okamotoi in the experimentally infected tiger puffers, the result of the experiments are shown in Table 2. Single dose administration of $25 \mathrm{mg} / \mathrm{kg}, 50 \mathrm{mg} / \mathrm{kg}$ and $100 \mathrm{mg} /$ $\mathrm{kg}$ of the drug were not effective, however, administration of the drug at $50 \mathrm{mg} / \mathrm{kg}$ fish body weight for 2 consecutive days resulted in an efficacy rate of $61.1 \%$ against the immature worms on the gills, which was significantly different as compared with that in the controls.

The results of the natural infection study are shown in Table 3. At the dose of $12.5 \mathrm{mg} / \mathrm{kg}$ for 5 days, 25 $\mathrm{mg} / \mathrm{kg}$ for 5 days and $50 \mathrm{mg} / \mathrm{kg}$ for 3 days, the drug was effective against the mature worms of $H$. okamotoi, with the reduction rates of $88 \%, 96 \%$ and $94 \%$, respectively, the corresponding reduction rates of the immature worms were $97 \%, 95 \%$ and $97 \%$, respectively. All of these results were significantly different from the rates in the control.

No abnormal fish, such as those showing defective feeding, was noticed in any of the experiments.

\section{Discussion}

The present study result clearly showed that following oral administration in tiger puffer, febantel was rapidly metabolized into fenbendazole and its metabolites, because the concentration of febantel in the plasma was markedly lower and the peak was reached significantly earlier than that of oxfendazole sulphone. These 
results are similar to those that have been observed in other animals (Baert et al., 1993; Debackere et al., 1993; Ben-Zvi et al., 1996).

In addition, the results of administration studies showed that febantel was effective against $H$. okamotoi, and that febantel was more effective in consecutive administrations of the drug rather than in a single administration. In this study, a single dose of 25,50 or $100 \mathrm{mg} / \mathrm{kg}$ of febantel was not effective, whereas administration of febantel at $50 \mathrm{mg} / \mathrm{kg}$ for two days was significantly effective against the immature worms on the gills. With regard to drugs effective against fish parasites, it has been reported that benzimidazole, fenbendazole and triclabendazole are effective by immersion against infection by Gyrodactylus sp. of rainbow trout Oncorhyncohus mykiss (Tojo et al., 1992), while orally administered triclabendazole and nitroscanate are also effective against this infection (Tojo and Santamarina, 1998). More importantly, administration of febantel at doses of $12.5 \mathrm{mg}, 25 \mathrm{mg}$ and $50 \mathrm{mg}$ for 3 or 5 consecutive days demonstrated that not only immature worms, but also mature ones were eradicated. This is the first report to present evidence of the efficacy of orally administered benzimidazole against mature worms of $H$. okamotoi. This finding may be significant, as the amount of blood ingested by mature worms is significantly greater than that ingested by immature worms (Ogawa et al., 2005), and the only medicine against $H$. okamotoi that has been used until now in culture field is hydrogen peroxide, which mainly attacks immature worms.

\section{References}

Anshary, H., K. Ogawa, M. Higuchi and T. Fujii (2001): A study of long-term change in summer infection levels of Japanese flounder Paralicthys olivaceus with the monogenean Neoheterobothrium hirame in the central Sea of Japan, with an application of a new technique for collecting small parasites from the gill filaments. Fish Pathol., 36, 27-32. Baert, L., S. van Poucke, H. Vermeersch, J. P. Pemon, J. Vercruysse, P. Bastiaensen and P. Debackere (1993): Pharmacokinetics and anthelmintic efficacy of febantel in the racing pigeon (Columba livia). J. Vet. Pharmacol. Therap., 16, 223-231.

Ben-Zvi, Z., E. Gussarsky, C. van Creveld and R. Yagil (1996): The bioavailability of febantel in dehydrated camels. J. Vet. Pharmacol. Therap., 19, 288-294.

Chigasaki, M., M. Nakane, K. Ogawa and H. Wakabayashi (2000): Standardized method for experimental infection of tiger puffer Takifugu rubripes with oncomiracidia of Heterobothrium okamotoi (Monogenea: Diclidophoridae) with some data on the oncomiracidial biology. Fish Pathol., 35, 215-221.

Debackere, M., J. Landuyt, J. Vercruysse and Q. McKellar (1993): The influence of Ostertagia circumcincta and Trichostrongylus colubriformis infections on the pharmacokinetics of febantel in lambs. J. Vet. Pharmacol. Therap., 16, $261-274$.

Lacey, E. (1990): Mode of action of benzimidazoles. Parasitol. Today, 6, 112-115.

Okamoto, R. (1963): On the problems of monogenetic trematode infection of puffers from the Inland Sea of Japan. Suisanzoshoku, Special Issue No. 3, 17-29. (In Japanese).

Ogawa, K. and K. Inouye (1997): Heterobothrium infection of cultured tiger puffer, Takifugu rubripes -A field observation. Fish Pathol., 32, 15-20.

Ogawa, K. and H. Yokoyama. (1998): Parasitic diseases of cultured marine fish in Japan. Fish Pathol., 33, 303-309.

Ogawa, K., M. Yasuzaki and T. Yoshinaga (2005): Experiments on the evaluation of the blood feeding of Heterobothrium okamotoi (Monogenea: Diclidophoridae). Fish Pathol., 40, 169-174.

Tojo, J., M. T. Santamarina, F. M. Ubeira, J. Estevez and M. L. Sanmartìn (1992): Anthelmintic activity of benzimidazoles against Gyrodactylus sp. infecting rainbow trout Oncorhynchus mykiss. Dis. Aqut. Org., 12, 185-189.

Tojo, J. and M. T. Sanmartìn (1998): Oral pharmacological treatment for parasitic disease of rainbow trout Oncorhynchus mykiss. II: Gyrodactylus sp. Dis. Aqut. Org., 33, 187-193.

Wollweber, H., H. Kölling, A. Widdig, H. Thomas, H.-P. Schulz and P. Mürmann (1978): Febantel, a new broad-spectrum anthelmintic. Arzneim. Forsch., 28, 2193-2195. 